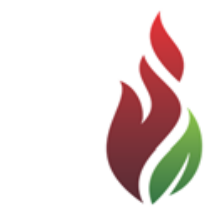

SUSTENERE

Publishing Corporation

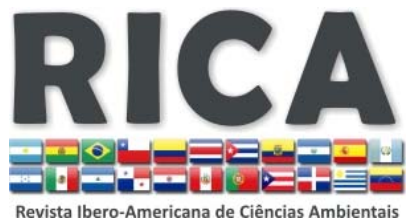

Journals Homepage:

www.sustenere.co/journals

\section{A FIBRA DA CASCA DO COCO VERDE E A FABRICAÇÃO DE BRIQUETES: UM ESTUDO DE SUAS POTENCIALIDADES}

\section{RESUMO}

A desequilibrada relação estabelecida pelo ser humano entre produção, consumo e descarte tem revelado problemas sérios na contemporaneidade, dentre eles o aumento do volume de casca de coco verde na composição do lixo urbano. Por isso, cada vez mais tem se buscado alternativas capazes de dirimir esta questão como o caso do briquete, usado como fonte de energia. Nesta perspectiva este artigo tem por objetivo levantar as potencialidades do emprego da fibra de casca de coco na produção de briquetes, analisando sua contribuição à redução de impactos ambientais, à verificação do tipo e do nível de benefícios econômicos e sociais.

PALAVRAS-CHAVES: Briquete; Casca de coco; Biomassa; Aproveitamento; Potencialidades.

\section{TA GREEN COCONUT BARK FIBER AND THE MANUFACTURE OF BRIQUETTES: A STUDY OF THEIR POTENTIAL}

\section{ABSTRACT}

The unbalanced human relationship established between production, consumption, and disposal have revealed serious problems in contemporary times, among them the increased volume of coconut shell green in the composition of urban waste. So, increasingly has sought to settle this matter capable alternatives such as briquette, used as an energy source. In this perspective this article aims to raise the employment potential of the Coconut husk fibre in the production of briquettes, analyzing its contribution to the reduction of environmental impacts, the determination of the type and level of economic and social benefits.

KEYWORDS: Briquette; Coconut Shell; Biomass; Exploitation; Potential.
Revista Ibero-Americana de

Ciências Ambientais, Aquidabã, v.5, n.1, Dez 2013, Jan, Fev, Mar, Abr, Mai 2014.

ISSN 2179-6858

\section{SECTION: Articles}

TOPIC: Tecnologia Industrial e Meio Ambiente

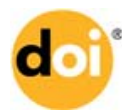

DOI: 10.6008/SPC2179-6858.2014.001.0023

Daniela Venceslau Bitencourt Universidade Federal de Sergipe, Brasil http://lattes.cnpq.br/8953756594341317 daniela.aju@hotmail.com

Alceu Pedrotti

Universidade Federal de Sergipe, Brasil http://lattes.cnpq.br/5022174893387665 alceupedrotti@ufs.br

Ronise Nascimento Almeida Universidade Federal de Sergipe, Brasil http://lattes.cnpq.br/9525607461160440 ronisedealmeida@hotmail.com

Received: 09/03/2013

Approved: 15/03/2014

Reviewed anonymously in the process of blind peer.

\section{Referencing this:}

BITENCOURT, D. V.; PEDROTTI, A.; ALMEIDA, R. N.. A fibra da casca do coco verde e a fabricação de briquetes: um estudo de suas potencialidades. Revista Ibero-Americana de Ciências Ambientais, Aquidabã,

v.5, n.1, p.319-328, 2014. DOI: http://dx.doi.org/10.6008/SPC2179$\underline{6858.2014 .001 .0023}$ 


\section{INTRODUÇÃO}

Ao longo da trajetória do ser humano no planeta, ele desenvolveu mecanismos que pudessem suprir suas necessidades. Contudo este processo acabou se estruturando a partir de uma desequilibrada equação: retirar, consumir e descartar. É exatamente nesta ponta da equação que se encontra um dos principais problemas que assola a sociedade moderna - a produção de resíduos sólidos.

O problema ganha contornos ainda mais acentuados quando se pensa as cidades litorâneas que vivem do turismo e que apresentam um aumento no consumo da água de coco in natura, visto que este aumento vem gerando cerca de 6,7 milhões de toneladas de casca/ano, transformando-se em um sério problema ambiental, principalmente para as grandes cidades. Só para se ter uma ideia, assegura Senhoras (2003), cerca de $70 \%$ do lixo gerado no litoral dos grandes centros urbanos do Brasil é composto por cascas de coco verde, material de difícil degradação e que, além de foco e proliferação de doenças, vem diminuindo a vida útil de aterros sanitários.

Embora o panorama possa aparecer assustador, existem projetos voltados para o reaproveitamento da casca de coco que desenvolvem um trabalho voltado não só para a problemática do meio ambiente, mas também com questões que envolvem a inclusão social. Tais soluções parecem crescer, principalmente nos grandes centros urbanos onde o problema tem dimensões alarmantes. Os empreendimentos que se voltam para a reutilização ou reciclagem da casca do coco produzem novos produtos como vasos, placas, tutores, vasos de parede, substratos, adubo orgânico e principalmente o uso da fibra na produção de briquetes. Nota-se que além dos benefícios ambientais, esta dinâmica torna-se ainda uma poderosa geradora de emprego e renda, criando postos de trabalho e oportunidades de uma vida melhor para todos.

Nesta perspectiva, o presente trabalho objetiva levantar as potencialidades do emprego da fibra de casca de coco na produção de briquetes, analisando sua contribuição à redução de impactos ambientais, à verificação do tipo e do nível de benefícios econômicos e sociais. Para tanto, realizou-se uma pesquisa aplicada, pois objetiva aplicar conhecimentos dirigidos à solução de problemas específicos, no caso o aproveitamento do resíduo do coco verde para geração de energia.

Os impactos gerados pelo resíduo do coco verde relacionados com o meio ambiente, foram identificados por meio da pesquisa bibliográfica, por observações feitas na área de estudo: a cidade de Aracaju e nos locais de disposição dos mesmos. A avaliação do potencial de aproveitamento do resíduo do coco verde para geração de energia, incluindo a forma de armazenamento e coleta além do mercado consumidor do material produzido foi desenvolvida com base na análise dos dados existentes e informações levantadas na área de estudo. 


\section{REVISÃO TEÓRICA}

\section{Biomassa e Briquetes: Aspectos Gerais}

A utilização de resíduos vegetais (galhos, casca de arroz,café e coco, bagaço, serragem, etc.) como combustível representa uma interessante alternativa aos combustíveis sólidos tradicionais (lenha e carvão). O modo mais fácil e simples de utilizar o poder calorífico destes materiais é a combustão direta. Entretanto, esta prática apresenta algumas desvantagens:

- Os resíduos vegetais possuem baixa densidade e muitos deles se encontram em forma de pó, provocando poeira e poluição, tornando difícil e caro o manuseio, o transporte, o armazenamento e seu uso como combustível.

- A maioria dos resíduos agroflorestais contém elevada umidade. Portanto, entre 18 e $20 \%$ do calor gerado na combustão é consumido para secar a própria biomassa, perdendo assim grande parte de seu potencial energético.

- A compactação dos resíduos vegetais em forma de briquetes (briquetagem) pode ser uma solução para alguns destes problemas.

A briquetagem de biomassa é uma prática muito antiga e uma das diversas técnicas que em termos gerais são classificadas como tecnologia de compactação. O processo de briquetagem consiste na aplicação de pressão em uma massa de partículas dispersas com objetivo de tornálas um sólido geométrico compacto de alta densidade. Esta operação pode ser realizada com ou sem a presença de um agente aglutinante.

(SRIVASTAVA et al., 1995) relataram que a briquetagem, como tecnologia, foi inventada no começo do século XIX. Na segunda metade do século XIX foi desenvolvida a primeira máquina a pistão para produzir briquetes de turfa. Em 1923, a sociedade 'Pacific Coal and Wood' de Los Angeles estava já comercializando briquetes de resíduos de madeira, usando uma prensa especialmente projetada. Os briquetes eram cilíndricos, com diâmetro aproximado de $7,5 \mathrm{~cm}$ e comprimento de $25 \mathrm{~cm}$, amarrados com arame para manter a coesão durante o transporte. Relatos indicam que estes briquetes apresentavam excelentes propriedades de combustão.

Desde então várias outras aplicações e tecnologias de briquetagem foram implementadas em vários países do mundo. (BHATTACHARYA et al., 1989), após realizar um estudo sobre as prensas para compactação de biomassa, encontraram 152 produtores no mundo, sendo a maioria concentrada na Alemanha. Existem vários mecanismos que permitem a ligação entre as partículas da biomassa compactada, e geralmente todos eles colaboram para obter a resistência e a coesão final do briquete. Grover e Mishra (1996) identificaram os seguintes mecanismos: Ação de aglutinantes (já presentes na matéria-prima ou adicionados); Forças de Van Der Waals; Forças de valência; Emaranhamento (entrelaçamento) entre partículas.

Os compostos ligantes que já estão presentes na matéria-prima podem ser ativados pelas elevadas pressões e temperaturas alcançadas no processo de compactação. Pode ser o caso da lignina, presente nas células da biomassa, que amolece entre 100 e $190^{\circ} \mathrm{C}$ e age como uma cola 
entre as partículas. Os mecanismos de emaranhamento e a ativação de forças de valência e de Van Der Waals acontecem pela forte aproximação e deformação das partículas provocada pelas pressões de compactação. Mesmo depois da compactação, as partículas da matéria-prima ainda são perceptíveis.

Briquetes são produtos de alto poder calorífico, obtido pela compactação dos resíduos de madeira como o pó de serragem e as cascas vegetais como a casca de coco. Apresenta forma regular e constituição homogênea sendo muito utilizado para a geração de energia. É considerado uma lenha ou carvão ecológico de alta qualidade, feito a partir da compactação de resíduos lignocelulosicos, sob pressão e temperaturas elevadas.

A briquetagem, segundo Silveira é o processo de fabricação de briquete, que ocorre por meio da compactação de resíduo no qual é destruída a elasticidade natural das fibras do mesmo. Esta destruição pode ser realizada por dois processos: alta pressão e/ou alta temperatura. $\mathrm{O}$ processo provoca a 'plastificação' da lignina, que atua como elemento aglomerante das partículas dos resíduos ligno celulosicos, uma razão muito importante da não necessidade de adicionar produtos aglomerantes (resinas, ceras, dentre outros). Para que esta aglomeração tenha sucesso, necessita da presença de uma quantidade de água, compreendida entre 8 a $15 \%$ de umidade, e que o tamanho da partícula esteja entre 5 a $10 \mathrm{~mm}$.

Os briquetes são produzidos a partir de qualquer biomassa vegetal, matéria-prima que deve ser processada por uma briquetadeira, máquina com capacidade para processar entre 50 e $1000 \mathrm{~kg} / \mathrm{h}$ de resíduos. O pesquisador desenvolveu uma briquetadeira que está sendo fabricada por empresas da iniciativa privada. O equipamento deve ser dimensionado para atender a cada propriedade e ter um custo de investimento e operacional compatível.

\section{A Fibra da Casca de Coco}

A estrutura do coco é formada de epicarpo, mesocarpo, endocarpo e semente; sendo fibra o nome dado ao material fibroso que constitui o mesocarpo. As fibras vegetais são formadas por diversos componentes químicos constituídos a base de Hidrogênio $(H)$ e Carbono $(C)$, sendo os principais a celulose, a hemicelulose e a lignina.

A celulose é um polissacarídeo formado por resíduos de D-glicopiranoses que formam longas cadeias lineares com alto grau de polimerização (formação de polímeros), se constitui na principal componente de todas as fibras vegetais, pois confere a mesma resistência mecânica.

A hemicelulose é constituída por uma mistura de polissacarídeos amorfos com grau de polimerização de 10 a 100 vezes menor que o da celulose. Em células maduras a hemicelulose encontra-se mais associada a lignina do que a outros polissacarídeos. A lignina é constituída por polímero complexo de estrutura amorfa, com componentes aromáticos e alifáticos, que se associa a celulose e hemicelulose durante a formação da parede celular dos vegetais e tem como 
finalidade conferir rigidez a mesma. Sua concentração nas fibras influencia a estrutura, as propriedades, a morfologia, a flexibilidade e a taxa de hidrólise.

Cada fibra vegetal é constituída de várias fibras elementares ligadas entre si por um material de cementação, formado principalmente por lignina. A Figura 1 mostra a constituição estrutural de uma fibra elementar, que possui uma parede espessa formada por diversas microfibrilas de celulose que formam espirais ao longo do eixo da fibra, tendo um lúmen no centro.

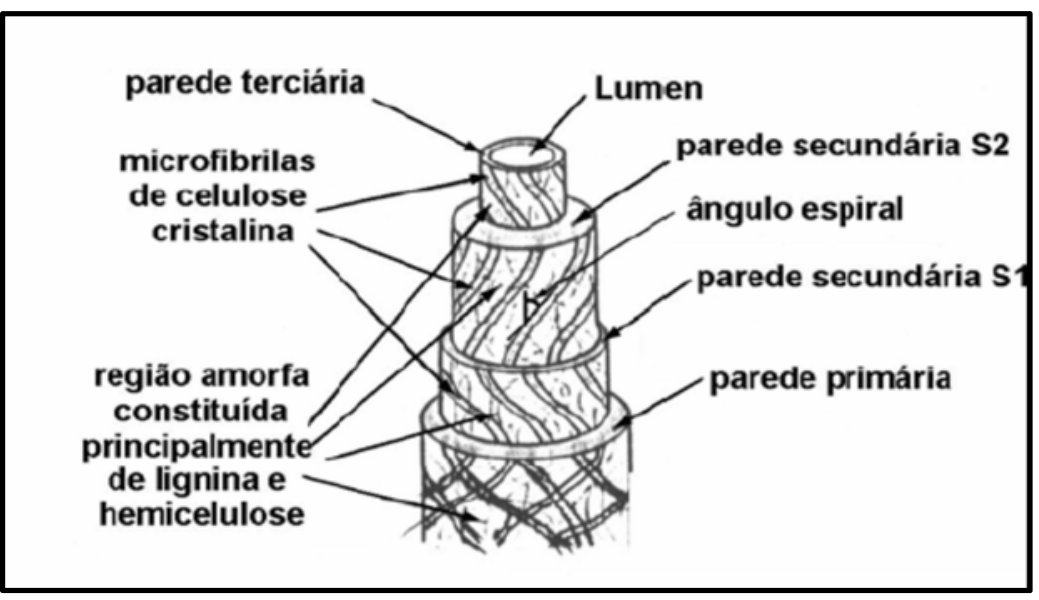

FIGURA 1: Constituição estrutural de uma fibra vegetal.

Fonte: Rong et al. (2001 citado por Silva, 2003).

Conforme assegura Nunes o aumento do volume da casca de coco levou a construir uma tecnologia que permitisse a biodegradação da casca de coco no menor tempo possível, transformando-a em matéria-prima para a confecção de produtos ou ainda na fabricação de adubos orgânicos como alternativa agroecológica para os sistemas de produção agrícola e, como nova fonte de renda para comunidades rurais. Essa tecnologia pode ser empregada tanto no aproveitamento da casca do coco seco quanto a do coco verde estrutura o processo de reciclagem nas seguintes etapas:

\section{Coleta do Resíduo (Cascas de Coco Verde)}

A coleta é feita diariamente e preferencialmente de modo que não ultrapasse 24 horas entre a extração da água até o processamento. Este procedimento tem como finalidade elevar a qualidade dos produtos finais (pó e fibra), pois a desidratação da casca prejudica as etapas subseqüentes do processamento.

\section{Recepção do Resíduo de Coco Verde}

O veículo que transporta os resíduos deve despejar a carga em uma baia de recepção, localizada na entrada da linha de processamento. Neste momento são retirados os materiais indesejáveis como: canudos, plásticos, pedras, cascas ressecadas podres, entre outros. Vale 
ressaltar a importância de manter um fluxo uniforme de alimentação da linha de processamento, que é feito por meio de um elevador (que tem velocidade controlada), para garantir a eficiência da prensagem.

\section{Trituração}

Nesta etapa, o resíduo é cortado e triturado por meio de facas rotativas em disco, as quais fazem o fatiamento da casca e em seguida passa por martelos fixos os quais são responsáveis pelo esmagamento do produto. Este procedimento possibilita a realização da etapa de seleção da fibra com o pó do coco e prensagem.

\section{Prensagem para Retirada da Umidade e Sais}

A casca de coco verde tem aproximadamente $85 \%$ de umidade e a maior parte dos sais se encontra em solução. Na prensagem, remove-se $60 \%$ da umidade, ou seja, é liberada a água que se encontra livre dentro dos elementos anatômicos (água de embibição), o que acarreta também na remoção conjunta dos sais. A eficiência desta etapa é de grande importância para a perfeita seleção do material na etapa seguinte e também para a adequação do nível da salinidade do pó obtido no processamento. O líquido oriundo da prensagem, chamado de Liquido da Casca de Coco Verde - LCCV é conduzido por meio de calha para a rede de esgotamento sanitário do município a fim de ser tratado.

\section{Seleção de Fibra e Pó}

Após a prensagem, as fibras são separadas do pó por meio de uma máquina classificadora que é equipada com um rolo de facas fixas e uma chapa perfurada. O material é turbilhonado ao longo do eixo da máquina e por diferença de densidade, o pó cai pela chapa perfurada e a fibra sai no fim do percurso.

\section{Peneiramento das fibras}

É utilizada uma peneira grossa para retirar pequenas impurezas que vêm com as fibras (por exemplo: pó e restos de endocarpo do coco) a fim de conferir qualidade ao produto final para comercialização. Há necessidade de secar as fibras (ao sol, ao vento ou utilizando ar quente) por aproximadamente 02 horas para remoção de umidade. Vale ressaltar que a máquina classificadora, por densidade, lança as fibras e acumula pequenos pedaços do endocarpo, ou seja, a quantidade de endocarpo que vai misturado com as fibras é mínima. 


\section{Tratamento Térmico do Pó}

Para utilização do pó da casca de coco, é necessário que o mesmo esteja isento de microrganismos fito patogênicos. Por isso, o pó pode ser submetido a um tratamento térmico, em forno rotativo, a $80^{\circ} \mathrm{C}$ durante 20 minutos. No caso da usina da Embrapa do Ceará, citada por Silveira (2008), o pó é colocado em leiras, onde é feito o reviramento diário e o controle da temperatura, até que haja a estabilização do produto final (em torno de 90 dias). As leiras ficam em locais cobertos para que não haja contaminação do produto, principalmente com fezes de pássaros. No final do processo é feito o peneiramento do produto para retirada das fibras curtas. Essas etapas podem ser sintetizadas na figura abaixo:

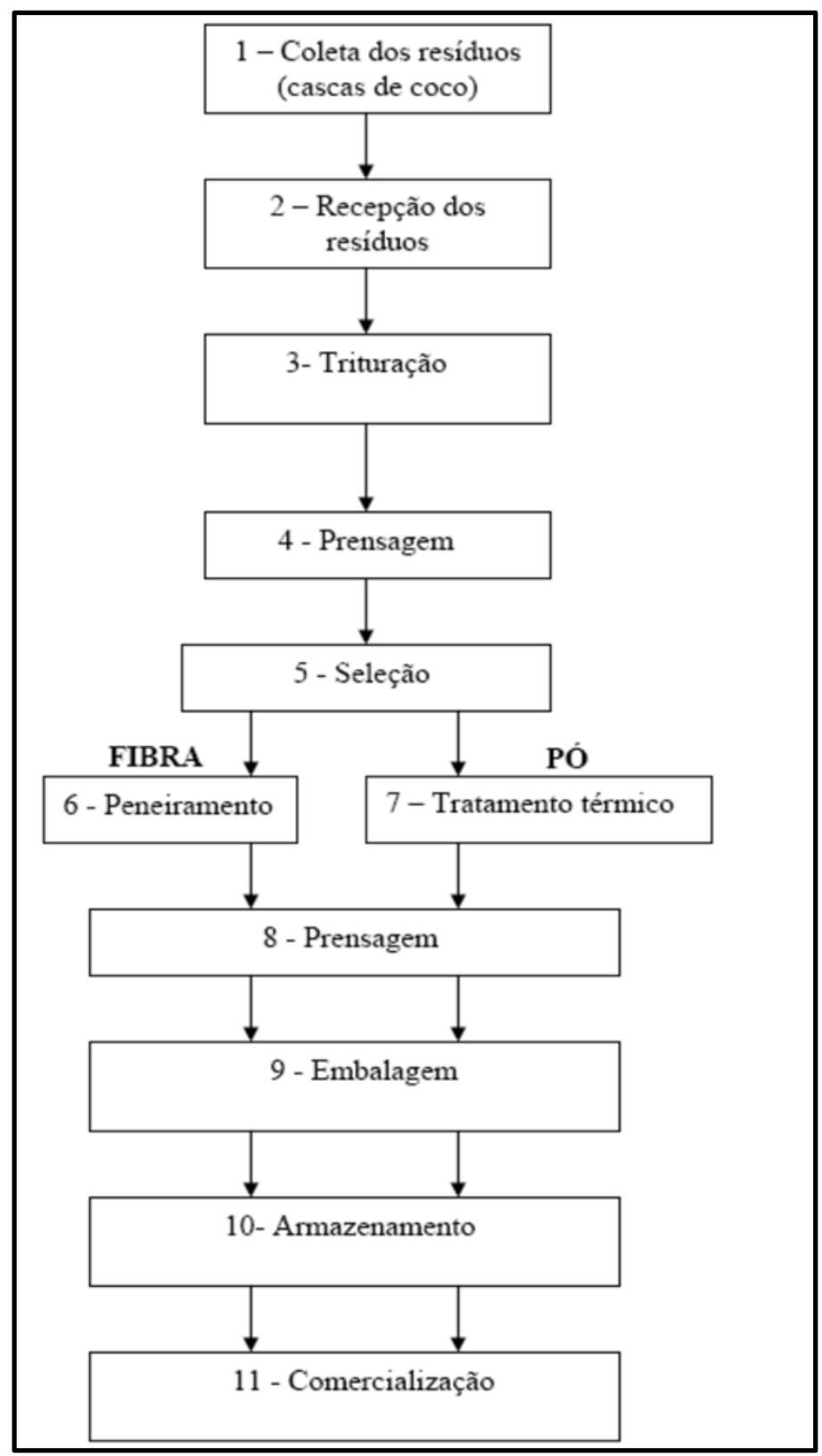

Figura 2: fluxograma operacional da usina. Fonte: Silveira (2008), adaptado da comunicação pessoal de Luiz Veras da Embrapa Agroindústria Tropical, 2007. 


\section{RESULTADOS}

A construção de uma usina para produção de briquetes a partir da fibra de casca de coco verde emerge como um empreendimento sustentável que agrega valores importantes na busca por alternativas sustentáveis que contribua para que o ser humano possa continuar desenvolvendo estratégias para atender suas necessidades, de modo a equilibrar a equação, pois a sustenta em três pilares: econômico, social e ambiental.

O aproveitamento do resíduo do coco verde para geração de energia por meio da produção de briquetes constitui no uso sustentável de biomassa como combustível não incrementando o teor de $\mathrm{CO} 2$ na atmosfera, já que este é produzido durante a combustão equilibrando-se com o $\mathrm{CO} 2$ consumido durante a fotossíntese.

O aproveitamento das cascas de coco verde surge como uma oportunidade de aumentar a vida útil dos aterros, devido a não disposição deste resíduo, já que 2,4 m2/dia é a área ocupada pelas cascas de coco que poderia abastecer a usina na alta estação; reduzir a emissão de metano para a atmosfera, melhorar a saúde pública devido a menor proliferação de vetores que transmitem doenças ao homem, acabar com o impacto visual causado pelo armazenamento e coleta inadequados, agregar valor a um resíduo, reduzir os gastos com a limpeza pública, gerar emprego e renda para uma classe social menos favorecida e profissionais com mão-de-obra qualificada que estejam desempregados, diminuir o impacto causado pela supressão de vegetação nativa para o uso de lenha e conscientizar/orientar a população do quanto é importante reduzir e aproveitar os resíduos.

Do ponto de vista econômico, os briquetes são destinados aos estabelecimentos e indústrias que possuem fornalhas, fornos, caldeiras e que utilizam lenha para gerar energia; eles substituem, com vantagem, a lenha; à medida que reduz custos, facilita o transporte, a manipulação e o armazenamento. Seu formato cilíndrico padronizado reúne uma alta densidade de resíduos prensada, sem a adição de produtos químicos ou aglutinantes, com alto poder calorífico.

Para Silveira, o custo aproximado para a implantação da usina de briquetagem, com os equipamentos convencionais vendidos no mercado, é de $\mathrm{R} \$ 375.900,00$, sendo o custo com a energia em torno de $\mathrm{R} \$ 6.411,24 /$ mês. Para a alternativa 02 onde o uso de equipamentos alternativos foi incorporado ao processo, os custos com os equipamentos e com a energia são $\mathrm{R} \$$ $258.000,00$ e $\mathrm{R} \$ 2.621,32 /$ mês, respectivamente. O ganho referente à venda do produto que atualmente, segundo informações da Nacbriquetes e Eco industrial, varia entre R\$ 310 a 500,00 a tonelada para serragem prensada, que já é um referencial.

Socialmente, desenvolvem-se oportunidades de geração de emprego e renda contribuindo para a fixação da população local e melhoria dos índices de desenvolvimento humano. Uma vez que para atender a uma produção de $536 \mathrm{~kg}$ de briquetes em aproximadamente uma hora, considerando uma briquetadeira com capacidade de produção de $600 \mathrm{Kg} / \mathrm{h}$. A usina operando por 
seis horas diariamente seria necessária a coleta de $25.182 \mathrm{~kg}$ de cascas de coco para produzir $3.210 \mathrm{Kg}$ de briquetes em aproximadamente seis horas de trabalho

O sucesso pleno da unidade empreendedora estará na estrutura de co-gestão desenvolvida a partir da criação de uma associação que conduzirá de forma participativa o gerenciamento do projeto em busca da sustentabilidade e do fortalecimento. Assim, como se pode observar ao longo deste trabalho, o uso dos rejeitos da casca de coco como matéria-prima se apresentou como alternativa viável tanto na perspectiva ambiental, quanto social e econômica. Para Silveira, para o gerenciamento e operação da usina, deve ser necessário criar uma Cooperativa a qual pode ser pública, privada ou mista. Os próprios vendedores de água de coco verde (barraqueiros e ambulantes) poderiam participar da Cooperativa separando as cascas do coco verde dos outros resíduos e acondicionando-o para a coleta, fazendo parte da equipe de separação os outros cooperados fariam parte das equipes de coleta, beneficiamento e entrega do produto final.

Essas medidas reforçam que é possível materializar ações que promovam a preservação do meio ambiente somada à capacidade de gerar emprego e renda, fortalecendo o associativismo e os mecanismos para que os indivíduos possam efetivar o exercício pleno da cidadania, numa proposta capaz de proporcionar um equilíbrio entre meio ambiente e desenvolvimento.

\section{CONCLUSÕES}

O conjunto de impactos gerados pela disposição das cascas de coco verde configura um fato importante na atualidade, principalmente, devido a escassez de áreas para implantação de aterros sanitários, a emissão de metano que contribui para o aumento do aquecimento global, a proliferação de vetores que pode acarretar em propagação de doenças e a poluição visual que afasta as pessoas do local diminuindo o fluxo comercial e consequentemente a renda dos comerciantes.

A avaliação do potencial de aproveitamento das cascas de coco verde para produção de briquetes implica a redução dos impactos causados com a disposição destas cascas e ainda contribui para a preservação da vegetação nativa devido a substituição da lenha por este produto.

O aproveitamento das cascas de coco verde surge como uma oportunidade de aumentar a vida útil dos aterros, devido a não disposição deste resíduo, já que 2,4 m2/dia é a área ocupada pelas cascas de coco que poderia abastecer a usina na alta estação; reduzir a emissão de metano para a atmosfera, melhorar a saúde pública devido a menor proliferação de vetores que transmitem doenças ao homem, acabar com o impacto visual causado pelo armazenamento e coleta inadequados, agregar valor a um resíduo, reduzir os gastos com a limpeza pública, gerar emprego e renda para uma classe social menos favorecida e profissionais com mão-de-obra qualificada que estejam desempregados, diminuir o impacto causado pela supressão de 
vegetação nativa para o uso de lenha e conscientizar/orientar a população do quanto é importante reduzir e aproveitar os resíduos.

\section{REFERÊNCIAS}

BHATTACHARYA, S. C.; SETT, S.; SHRESTHA, R. M.. State of the art for biomass densification. Energy Sources, New York, v.11, n.3, p.161-182, 1989.

BORGES, M. R.. Projeto de construção de uma unidade de beneficiamento da fibrada casca do coco verde em Cuiabá. Fortaleza: EMBRAPA E SEBRAE, 2005.

BRAUSS, F. E.. The chemistry of lignin. Academic Press INC: New York, 1952.

GROVER, P. D.; MISHRA, S. K.. Biomass Briquetting: technology and practices. Bangkok: Food and Agriculture Organization of the United Nations, 1996.

LORA, E. E. S.. Prevenção e controle da poluição nos setores energético, industrial e de transporte. Rio de Janeiro: Editora interciência, 2002.

NUNES, M. U. C.. Tecnologia para biodegradação de casca de coco-seco e de outros resíduos do coqueiro. Circular Técnica 46. Aracaju, 2007.

SENHORAS, E.. Estratégia de uma agenda para a cadeia agroindustrial do coco. Campinas: ESC, 2003 SRIVASTAVA, P. K.; MAHESHWARI, R. C.; OJHA, T. P.. Biomass briquetting and utilization, New Delhi: Jain Brothers, 1995.

SRIVASTAVA, P. K.; MAHESHWARI, R. C.; OJHA, T. P.. Biomass briquetting and utilization, New Delhi: Jain Brothers, 1995.

STAUBER, E.. Machine for disintegrating and Compresing peat. US Patent: 1895.

SILVEIRA, M. S.. Aproveitamento das cascas de coco verde para produção de briquetes em SalvadorBA. Dissertação (Mestrado) - Universidade Federal da Bahia. Salvador, 2008.

SILVA, R. V.. Compósito de resina poliuretano derivada de óleo de mamona e fibras vegetais. Tese (Doutorado) - Universidade de São Paulo. São Carlos, 2003.

PASSOS, P. R. A.. Destinação sustentável de cascas de coco verde: Obtenção de telhas e chapas de partículas. Tese (Doutorado) - Universidade Federal do Rio de Janeiro. Rio de Janeiro, 2005.

SILVA, R. V.. Compósito de resina poliuretano derivada de óleo de mamona e fibras vegetais. Tese (Doutorado) - Universidade de São Paulo. São Carlos, 2003.

SILVEIRA, M. S.. Aproveitamento das cascas de coco verde para produção de briquetes em SalvadorBA. Dissertação (Mestrado) - Universidade Federal da Bahia. Salvador, 2008.

SILVEIRA, M. S.. Aproveitamento das cascas de coco verde para produção de briquetes em SalvadorBA. Dissertação (Mestrado) - Universidade Federal da Bahia. Salvador, 2008. 